\title{
Cenglesto
}

\section{Recortes de jornal em arquivos: origens de uma prática social}

\author{
José Francisco Guelfi Campos \\ Doutor; Universidade Federal de Minas Gerais, Belo Horizonte, MG, Brasil. \\ jfgcampos@ufmg.br
}

\begin{abstract}
Resumo: A presença de recortes de jornal em arquivos, sobretudo aqueles de natureza pessoal, para além de impor uma série de desafios teóricos e práticos, permite cogitar que a acumulação deste tipo de material reflita uma prática social ainda pouco estudada. Neste artigo, procuramos traçar a origem desta prática social e examinar suas várias manifestações nos arquivos. Trata-se de estudo exploratório, lastreado por revisão de literatura e fundamentado em pesquisa documental. A revisão da literatura aponta para a conexão entre a prática de acumulação de recortes e uma longa e rica tradição de produção de scrapbooks, que vai de encontro às necessidades informacionais dos indivíduos, à materialização dos laços afetivos e à acumulação de capital cultural. Na pesquisa documental, os exemplos extraídos de arquivos pessoais revelam os atributos funcionais adquiridos pelos recortes quando fazem parte de um fundo, determinados pelos contextos de acumulação e uso. Por fim, demonstramos como tais atributos credenciam os recortes de jornal como documentos passíveis de tratamento ancorado nos princípios e procedimentos próprios da Arquivologia, reforçando a primazia do contexto sobre o conteúdo e a importância da definição das espécies e tipos documentais, para o que se faz necessário o diálogo com outros campos disciplinares, entre os quais a Diplomática, as Ciências da Comunicação, a Teoria do Jornalismo e a Linguística.
\end{abstract}

Palavras-chave: Recortes de jornal. Cadernos de Recortes. Prática social. Arquivos pessoais. Tipologia documental.

\section{Introdução}

Para quem trabalha com arquivos, especialmente aqueles acumulados por pessoas, não deve ser novidade deparar-se com conjuntos, muitas vezes bastante volumosos, de recortes de jornal convivendo com os demais documentos que compõem um fundo. Fatia pouco apreciada nos arquivos, em comparação com outros documentos suspostamente mais charmosos ou reveladores da intimidade ou da identidade dos indivíduos, como bem notou Ana Maria Camargo (2009), os 
recortes de jornal têm sido sistematicamente relegados a uma zona indefinida no plano do arranjo e da descrição documental.

Os desafios impostos pelos recortes de jornal são muitos, e incidem sobre as várias etapas em que se organiza o quefazer arquivístico. O primeiro deles, talvez o mais sensível, tem a ver com a conservação preventiva. Como se sabe, o material que serve de suporte aos fragmentos de notícias, entrevistas, reportagens e tantos outros conteúdos jornalísticos encontrados nos arquivos sob o formato de recorte é frágil por natureza, e não é preciso muito tempo para que comece a ostentar as características que denunciam sua baixa qualidade. Mas, a despeito de todas as condições contrárias, os recortes de jornal perduram - amarelados, quebradiços - nos arquivos. A baixa gramatura e a elevada acidez do papel-jornal parecem determinar, cedo ou tarde, a autodestruição dos recortes. Como, então, protegê-los de si mesmos? E, mais, como proteger os demais documentos da acidez que insiste em irradiar dos recortes para atingir outras parcelas do acervo? Provavelmente estas são as duas primeiras questões que se colocam quando do tratamento de um arquivo que contenha volume expressivo de recortes de jornal.

Os outros problemas, não menos importantes, prescindem da extensão do conjunto documental. Basta um recorte para que o arquivista se pergunte onde encaixá-lo na lógica interior do fundo e como chamá-lo, isto é, que espécie ou tipo documental aplicar para designá-lo. São questões relevantes, cujas respostas podem afetar - positiva ou negativamente - o resultado final das duas funções primordiais executadas nos arquivos permanentes: o arranjo e a descrição. ${ }^{1}$

Não tem sido raro observar, nos instrumentos de pesquisa, a posição marginal ocupada pelos recortes de jornal. Neste sentido, vale destacar o procedimento preconizado por um dos mais difundidos manuais de organização de arquivos pessoais, que vem, há décadas, inspirando o método de trabalho em inúmeras instituições arquivísticas brasileiras: a separação dos recortes em série isolada e o descarte daqueles que se apresentem incompletos ou sem dados de identificação, como data ou título do jornal do qual foram destacados (CENTRO DE PESQUISA E DOCUMENTAÇÃO DE HISTÓRIA CONTEMPORÂNEA DO BRASIL, 1998). 
Outro recurso, igualmente impróprio, é agrupar os recortes de jornal em série denominada pela técnica de registro, fazendo-os figurar no grupo dos chamados documentos impressos, como se vê no inventário analítico do fundo Osvaldo Cardoso de Melo, custodiado pelo Arquivo Público Municipal de Campos dos Goytacazes, em que a série "Impressos" comporta duas subséries, preenchidas por recortes extraídos de jornais de Campos dos Goytacazes e do Rio de Janeiro (subsérie 05.01) e mapas que representam a geografia política no período da I Guerra Mundial (subsérie 05.02) (ARQUIVO PÚBLICO MUNICIPAL DE CAMPOS DOS GOYTACAZES, 2005).

O fato de que muitas vezes o conteúdo dos recortes não tenha sido produzido pelo titular do arquivo pode acarretar a adoção de outra estratégia, também capciosa, qual seja, a de reuni-los inadvertidamente num grupo ou numa série intitulada pela rubrica genérica "produção de terceiros". Tal medida, que à primeira vista parece solucionar o problema, cria outro muito maior e mais delicado, por fazer supor que todos os demais documentos que compõem o arquivo sejam da lavra de seu titular, o que claramente não se verifica quando se observa, por exemplo, a correspondência, composta, por excelência, muito mais de documentos recebidos do que de documentos produzidos pela entidade que os acumulou.

Quando se passa da representação da estrutura do fundo para a descrição dos itens que efetivamente a preenchem, isto é, das unidades documentais, emergem outros desafios. Fica evidente, então, o problema da definição das espécies e dos tipos documentais. Em alguns exemplos, percebe-se a adoção da descrição unitária orientada pelos elementos que constituem a referência bibliográfica, como se autoria, título e data de publicação bastassem para substituir a denominação da espécie ou para induzir a compreensão do conteúdo, do potencial informativo ou mesmo dos atributos funcionais que os recortes adquirem quando fazem parte de um arquivo. Em certos casos, é possível notar que a tentativa de identificar as espécies documentais esbarra no uso de expressões genéricas (como "matéria", "texto", "recorte"), ao lado de outros termos mais apropriados, como "nota" ou "artigo". O que se percebe, nestas 
situações, é que o esforço de definição das espécies parece se orientar mais pela intuição do que pelo exame das características estruturais internas e externas dos documentos. $^{2}$

Dar nome aos documentos, isto é, estabelecer e definir espécies e tipos documentais, não se trata de mera questão de requinte, mas de procedimento imperioso no trabalho cotidiano do arquivista, em primeiro lugar porque a tipologia documental se apresenta, ainda que esta noção não seja consensual, como base para a formação das séries. ${ }^{3}$ Em segundo, porque tem a ver com o reconhecimento daquilo a que chamamos identidade documental: "documentos pessoais", "correspondência" e "recortes de jornal" são exemplos de termos genéricos e coletivos largamente empregados para denominar todo um leque de documentos de natureza pretensamente semelhante que se manifestam nas esferas da identificação civil, dos atos de comunicação e no universo das matérias publicadas na imprensa periódica, mas que ostentam estruturas formais e semânticas próprias que os tornam, portanto, muito diferentes entre si.

Embora estas questões sejam, naturalmente, de interesse para estudiosos e profissionais de arquivo, o objetivo deste trabalho é outro. Não nos deteremos, aqui, nos problemas relativos à tipologia documental, algo que já discutimos em outras oportunidades. Em estudo anterior, do qual deriva este artigo, tratamos de explorar a relação entre a Arquivologia, a Diplomática e as Ciências da Comunicação e da Linguagem para a construção de um glossário de espécies documentais capazes de denominar os chamados recortes de jornal (CAMPOS, 2018) e pudemos perceber que a existência marcante deste tipo de material no interior dos arquivos pessoais pode ser compreendida como reflexo de uma prática social estimulada desde a primeira infância.

Neste sentido, pretendemos compartilhar algumas considerações a respeito do hábito de recortar, colar e guardar fragmentos dos produtos da imprensa periódica, prática que, ao que tudo indica, tem sua origem ancorada numa tradição muito mais antiga do que se supõe. Para tanto, combinamos a revisão de uma literatura especializada ainda escassa sobre os cadernos de recorte, com aportes das áreas da Sociologia e da Educação acerca do colecionismo, das 
práticas de leitura e das funções lúdico-pedagógicas dos exercícios de colagem. Transportando a reflexão para o universo dos arquivos, valemo-nos da pesquisa documental para fundamentar a discussão a respeito dos atributos funcionais da acumulação de recortes de jornal, a partir de casos concretos observados em fundos de natureza pessoal.

\section{Uma longa e rica tradição}

Compreender a acumulação de recortes de jornal como uma prática social implica perseguir os traços de sua manifestação, de modo a dotá-la de sentido histórico. Contudo, trata-se de um campo de estudos ainda pouco explorado, tanto no Brasil quanto no exterior. Ao que parece, os primeiros estímulos à prática do recorte surgem no ambiente escolar, logo nos primeiros anos da educação formal. Neste sentido, o diálogo com a literatura do campo da Pedagogia, especialmente os ramos dos fundamentos da educação pré-escolar e da história da educação, pode oferecer algumas pistas interessantes e valiosas.

Não é de hoje que a Pedagogia se ocupa de estudar as funções ligadas aos exercícios de recortar e colar, que já faziam parte, no século XVIII, das propostas de Fréderic Óberlin para a educação de crianças de quatro a sete anos de idade. Friedrich Fröebel, pedagogo alemão que em 1837 fundou o primeiro jardim de infância, preconizava o ensino por meio da brincadeira e do jogo, aliando a manipulação de bolas, cubos e cilindros ao canto e às ocupações manuais, entre as quais o recorte e a colagem (KISHIMOTO, 1995). Suas ideias encontraram solo fértil em experiências educacionais desenvolvidas em países europeus como a Alemanha, a Inglaterra e a Itália, e na América do Norte, especialmente nos Estados Unidos, tendo sido reproduzidas também em países da América Latina, entre os quais o Brasil (OLIVEIRA, 2011).

No campo da Medicina, estudiosos do desenvolvimento psicomotor apontam a importância da prática de recortar e colar para o aperfeiçoamento da coordenação fina da mão e dos dedos. Segundo Jean Le Boulch (1986), enquanto o manuseio da tesoura tende a desenvolver a boa dissociação dos dedos e a 
mobilidade do punho, a colagem colaboraria para a aquisição de leveza e precisão dos gestos, além de estimular a formação de combinações de formas e cores. As pedagogas catalãs Eulàlia Bassedas, Teresa Huguet e Isabel Solé (2007) também consideram a tesoura e o papel ferramentas valiosas para o favorecimento da motricidade fina, da capacidade de representação e da criatividade em crianças em idade pré-escolar. Outros pedagogos destacam, ainda, a função educativa das atividades de recorte e de criação de livros de figuras para o desenvolvimento das formas de comunicação e expressão e das linguagens gráfica e oral (MALUF, 2008), bem como para o processo de alfabetização, por meio de exercícios de formação de palavras recortadas de jornais, revistas, livros e embalagens (ALMEIDA, 2003).

Entendido como atividade lúdica, o ato de recortar e colar, para além de suas implicações pedagógicas, pode servir ao lazer, ao entretenimento. Ferramenta educativa e moral, como bem notaram Ott, Tucker e Buckler (2006, p. 9, tradução nossa), a prática não deixa de ser entendida como um meio "[...] de converter as crianças, de criaturas ferozes em bons cidadãos", ou uma forma de proporcionar às mães um pouco de merecido sossego, como sugere uma matéria publicada em meados dos anos 1950 nas páginas do suplemento feminino de $O$ Estado de S. Paulo:

[...] Está chovendo, seu filho não pode brincar lá fora. Tem apenas quatro anos, mas já sabe usar suas mãozinhas com certa habilidade. Dê-lhe uma tesoura de pontas redondas e experimente iniciá-lo na arte de recortar. Dê-lhe uma revista velha onde haja figuras de bichos, de objetos, de pessoas e mostre-lhe como deve fazer para cortar seguindo os contornos da figura. Ele se deliciará com este novo brinquedo. Naturalmente seus primeiros trabalhos serão informes, mas na próxima vez ele será mais bem sucedido e ficará satisfeito e orgulhoso de si, quando a tesoura, agora melhor dirigida, não mutilar mais as figuras. Assim você o terá algumas dezenas de minutos tranquilo e entretido e para interessá-lo mais, arranje uma caixinha bonita para guardar seus recortes. Você pode variar este brinquedo comprando folhas de papel de côres vivas e um vidro de cola branca em pasta. Se puder leva-lo consigo á loja e deixá-lo escolher, ele mesmo, as côres do papel, será ótimo. [...] Uma vez em casa, dobre e corte as folhas do papel de modo a torná-las do tamanho das folhas de um caderno escolar comum. Junte as folhas e costure um dos lados. O pequeno terá, assim, o seu primeiro caderno de recortes, no qual ele mesmo colará as figuras que julgar mais bonitas. E você verá com que satisfação e entusiasmo ele o folheará. Pouco a pouco vá aumentando as dificuldades. Á medida que ele fôr mostrando maior destreza, dê-lhe figuras mais difíceis de recortar. [...] É preciso que 
as mães se persuadam de que não são os brinquedos mais caros que trazem maior satisfação aos filhos. Aqueles que obrigam a pensar, a raciocinar, a usar as mãozinhas, além de seu valor educativo, proporcionar-lhes-ão maior alegria e serão os mais queridos. (SAIBA..., 1956, p. 50).

Atividade lúdica, que educa e dá prazer, a prática do recorte pode ser levada para a vida adulta, assumindo diferentes sentidos. Uma de suas manifestações mais banais parece se dar no âmbito da administração doméstica, nos afazeres cotidianos da dona de casa, para quem o suplemento feminino de $O$ Estado de S. Paulo dava, em 1973, orientações sobre como organizar um caderno de recorte para melhor preservar e consultar as receitas de cozinha:

Também não ajuda em nada o caderno grosso e bem encapado que você comprou para passar as receitas a limpo mas que continua em branco e cheio de recortes lá dentro que o deixam mais grosso ainda. [...] Compre um fichário (poderá ser do tipo escolar ou especializado com capa plastificada e que traz os dizeres "Fichário de Cozinha") à venda em várias lojas de São Paulo. Divida-o por capítulos, escrevendo em cada folha de cartolina divisória o título da especialidade [...] Sem pressa e com constância, as receitas escolhidas, sejam recortes de revistas, jornais, folhetos ou bilhetinhos ditados às pressas, serão presos em suas sessões correspondentes, poupando trabalho e o tempo da cópia. (NÃO...,1973, p. 61).

O hábito de colecionar recortes de jornal e outros materiais impressos, organizando-os em álbuns, fichários ou cadernos, remete a uma longa e rica tradição, “[...] uma das mais duradouras e, ao mesmo tempo, dinâmicas manifestações culturais dos últimos duzentos anos", no dizer de Katherine Ott, Susan Tucker e Patricia Buckler (2006, p. 1, tradução nossa), cujos vestígios mais primitivos podem ser localizados muito antes daquilo a que hoje chamamos, genericamente, imprensa periódica ou grande imprensa.

Para Katie Day Good (2013), o album amicorum, livro utilizado entre os séculos XVI e XVIII por estudantes (homens, brancos e aristocratas), parece ser o embrião dos cadernos de recortes que se tornaram tão populares a partir do século XIX. Num salto ousado, a autora vê neste tipo de álbum, e em outros espécimes dele derivados, os precursores das redes sociais largamente frequentadas na internet nos dias de hoje. Chamado, em inglês, de friendship 
book, que poderíamos traduzir por algo como "livro de amizades", o album amicorum se trata de um volume encadernado destinado à manutenção de registros ilustrados dos contatos travados pelos estudantes com colegas e professores que conheciam em suas viagens de formação pela Europa.

Alexander Broadley (1910), por seu turno, relaciona o album amicorum à origem da prática da coleção de autógrafos, chamando a atenção para o acervo do British Museum, do qual faz parte o álbum mais antigo que pôde localizar, datado de 1579 e pertencente à coleção "Sloane manuscripts". ${ }^{4}$ Pesquisando o banco de dados da instituição, pudemos localizar, em outra coleção, um exemplar ainda mais antigo, o album amicorum de Johannis Breijsgen, preenchido entre os anos de 1572 e 1577.5

Em sua origem, o livro de amizades já ostentava uma estrutura formular característica. Em suas páginas, havia um desenho ou um verso previamente inscrito em latim, grego ou hebraico, seguido de espaço em branco, reservado para que o amigo ou conhecido registrasse, de próprio punho, uma saudação ou dedicatória, geralmente acompanhada de um brasão ou de um pequeno emblema (ROSENTHAL, 2009).

O álbum de Jacob Heyblocq, composto por cerca de 300 páginas, quase todas preenchidas com dedicatórias e desenhos à mão livre entre 1645 e 1678, ${ }^{6}$ tem estrutura de certa forma já um tanto simplificada em relação àquela descrita por Margaret Rosenthal. Contudo, mantém o atributo funcional que caracteriza o album amicorum e que, mais tarde, vai se manifestar também nos livros e cadernos de autógrafos que floresceram na cultura norte-americana no começo do século XIX e que rapidamente se transformaram em passatempo popular: serve, em primeiro lugar, como objeto destinado à materialização dos laços sociais e afetivos (GOOD, 2013).

Nas raízes da tradição que culmina nos cadernos de recortes, tais como os conhecemos hoje, encontram-se ainda outros exemplares curiosos. Um deles é o commonplace book, cuja origem remete à cultura dos gabinetes de curiosidades. Nestes "cadernos de excertos" ou "cadernos de citações" se transcreviam, à mão, trechos de livros e periódicos para uso posterior em cartas (GOOD, 2013), além 
de palavras a serem empregadas em discursos e conversas. Tratava-se, segundo Ott, Tucker e Buckler (2006), de uma ferramenta mnemônica e meio de cultivo intelectual para o crescimento pessoal, um dispositivo para preservar o conhecimento e, ao mesmo tempo, colocá-lo em prática.

Como objetos entesourados, a funcionalidade destes álbuns se caracterizava pela expressão dos gostos cultivados. Não eram, portanto, criados para preservar algo para uma posteridade longínqua; pelo contrário, a produção destes espécimes parecia atender a um imperativo de ordem prática e imediata: eram feitos para ser exibidos e compartilhados socialmente e, assim, usados como dispositivos que conferiam distinção aos seus proprietários por meio da ostentação do capital cultural por eles acumulado. Para Pierre Bourdieu (2011), o capital cultural é o conhecimento acumulado por um indivíduo sobre a sociedade em que se insere e pode ser obtido por diversos meios, tais como a educação formal e as credenciais por ela conferidas, o conhecimento herdado, o cultivo do gosto estético e a aquisição de bens de alto padrão, e se trata de uma (quando não a principal) das formas de obtenção de distinção social.

Os confession albums, "álbuns de confissões" ou "cadernos de enquete"7, são também reflexo desta cultura. Populares desde o século XIX, caracterizam-se pela paradoxal combinação entre o caráter confessional e a indiscrição propositada. Passado de mão em mão entre amigos, o caderno de enquete se sustenta pela fórmula do questionário, com estrutura muito próxima àquela que, em meados do século XX, seria adotada pelos jornais e revistas para organizar o conteúdo das entrevistas, o "pingue-pongue", expressão que, no jargão jornalístico, equivale à "[...] entrevista editada na forma de diálogo, com perguntas e respostas." (RABAÇA; BARBOSA, 2001, p. 567). ${ }^{8}$

Figuras de grande projeção, como a escultora e artista gráfica Camille Claudel e o escritor Marcel Proust não se furtaram a responder enquetes a respeito de suas preferências, opiniões e aspirações. Em visita à casa de Florence Jeans, na Ilha de Wight, Claudel completou à mão, em maio de 1888, a enquete previamente impressa no caderno da amiga. O formulário - em que constavam perguntas como "sua virtude favorita", "características que mais admira em um 
homem", "seu ideal de felicidade", "sua cor e sua flor preferidas", "onde gostaria de viver?", "seus poetas prediletos" - é revelador do certo grau de frivolidade deste passatempo popular. ${ }^{9}$

Pela pretensa capacidade de revelar facetas e traços da personalidade dos indivíduos, estes cadernos tornaram-se objetos cultuados, hoje expostos em museus (o de Florence Jeans, em que consta a enquete respondida por Camille Claudel, encontra-se no Museu Rodin, em Paris) e reproduzidos em fac-símiles de luxo, como o de Proust, editado em volume que traz, ainda, enquetes respondidas por outras personalidades, como o arquiteto Richard Meier e pelas atrizes Brigitte Bardot e Marisa Berenson. Não deixam, também, de figurar como documentos de arquivo, como é o caso da "enquete entre colegas" respondida, em 5 de outubro de 1945, por Fernando Henrique Cardoso e seus companheiros do Colégio São Paulo - Célio, Luiz Carlos e Luiz Ventura -, composta por 12 perguntas, entre as quais algumas bastante curiosas: "qual sua condição política?" (eram quase todos socialistas, apenas Luiz Carlos se declarava democrata capitalista), "você é pró-constituinte?" (Luiz Carlos não era), "qual a sua pátria espiritual?" (a de Fernando Henrique e Luiz Ventura eram os Estados Unidos, Luiz Carlos e Célio preferiam a Suíça). ${ }^{10}$

Se o papel e a tinta parecem ser cada vez menos utilizados hoje em dia, as enquetes, contudo, não saíram de moda; renovaram-se, no que tange ao meio de transmissão e ao conteúdo, em face das novas tecnologias, e são agora respondidas por escrito ou em vídeo nos blogs, canais, murais, feeds e timelines das redes sociais. No entanto, a fórmula estrutural que as caracteriza se mantêm a mesma das enquetes do século XIX.

O incremento das técnicas de impressão em larga escala, no século XIX, determinou um novo estágio da cultura de produção de álbuns e cadernos, ligada à ostentação dos gostos cultivados, ao lazer e à promoção da sociabilidade: o nascimento dos cadernos de recortes. De passatempo predominantemente apreciado pelas elites e pelos membros de uma burguesia mais abastada, estes cadernos passaram a ganhar popularidade crescente junto a uma classe média 
fascinada pela profusão de material impresso - bonito, colorido e, sobretudo, barato - à sua disposição (GOOD, 2013).

Na América do Norte, pouco a pouco, os cadernos de recortes vão se tornando objetos de consumo, impulsionados pelo advento da impressão a vapor, da gravação em relevo e da cromolitografia, bem como pela expansão dos meios de transporte, que tornava possível a distribuição dos impressos aos lugares mais remotos. Produzidos em escala industrial e amplamente comercializados em papelarias, os álbuns ganharam incrementos interessantes, como páginas autocolantes, entrefolhas, encadernações mais resistentes e suportes mais duráveis e flexíveis para abrigar toda sorte de material: canhotos de recibos, cartões comerciais, figuras de catálogos, rótulos, embalagens e, por que não, recortes de jornal (GOOD, 2013; OTT; TUCKER; BUCKLER, 2006).

A expansão da imprensa periódica, que resultou em sensível aumento da quantidade de jornais e revistas em circulação no mercado norte-americano, especialmente na segunda metade do século XIX, além de colocar ainda mais material impresso à disposição dos aficionados pela distração de recortar e colar, fez emergir um problema de outra natureza, sentido por E. W. Gurley, autor de Scrapbooks: how to make them, manual originalmente publicado em 1880:

\footnotetext{
Notando sua própria inclinação para o colecionismo, ele [Gurley] atribuiu a febre pelos cadernos de recortes ao crescimento dos jornais, "de 2 nos tempos de Franklin a mais de 8000 em 1880". "Todos nós lemos, mas podemos dizer que estamos bem informados?", ele perguntava e sua resposta era negativa. O problema poderia ser resolvido se "lêssemos com algum propósito, procurássemos por algo específico e o guardássemos quando encontrado, e de nenhuma outra forma isso poderia ser tão bem preservado como nas páginas de um bom caderno de recortes." (OTT; TUCKER; BUCKLER, 2006, p. 9, tradução nossa).
}

Assim, a prática do recorte e da colagem, tributária da longa tradição da produção de álbuns cuja função primária vinculava-se principalmente à materialização ou à documentação dos laços de amizade, vai adquirindo novo atributo funcional no contexto da explosão das fontes de informação, inscrevendo-se no escopo das práticas de leitura. O ritual de recortar, colar e guardar, precedido - e ao mesmo tempo dele resultante - pelo exercício da leitura, 
passa a atender às necessidades dos indivíduos por informação, sem perder, com isso, seu caráter recreativo. Curiosamente, Michel de Certeau (2009, p. 236-263) compara a leitura a uma “operação de caça furtiva" e Lévi-Strauss (1989), por seu turno, oferece subsídios para compreendê-la como um exercício de bricolagem. Quando repletos de notícias, reportagens e outras matérias originalmente publicadas em jornais e revistas, colecionadas como material para referência futura ou para recirculação, os cadernos ou álbuns de recortes assumem um caráter eminentemente instrumental: são ferramentas que permitem às pessoas enfrentar uma avalanche de estímulos e de informação (GOOD, 2013).

\section{Os recortes nos arquivos}

Se, por um lado, estes cadernos e álbuns revestem, como notou Good (2013), três funções primárias que se desenrolam, intercalam e sobrepõem ao longo do tempo, sem que com isso excluam-se mutuamente - quais sejam, (1) documentar/materializar os laços afetivos, (2) navegar na abundância de fontes de informação e (3) atingir a distinção social por meio da ostentação do capital cultural acumulado -, por outro, não escapam à sorte de figurar como objeto de especulações análogas àquelas que incidem sobre os arquivos pessoais, sendo também compreendidos como espaços de construção de uma vida idealizada e como manifestações materiais da memória de quem os compilou e do ambiente cultural em que foram produzidos, comparáveis, neste sentido, aos palácios da memória da Antiguidade Clássica (OTT; TUCKER; BUCKLER, 2006).

Envoltos na bruma da privacidade que envolve a intimidade das pessoas ou criados para serem compartilhados e exibidos, os cadernos de recortes geralmente ostentam algo de excêntrico e idiossincrático, uma certa instabilidade típica das "miscelâneas", mesmo quando seu conteúdo se orienta por temas específicos ou é organizado segundo algum critério classificatório definido, como bem observou Ellen Garvey (2003). De acordo com Ott, Tucker e Buckler (2006), apesar de serem produtos da cultura de massa, os cadernos de recortes são únicos em sua individualidade, são autênticos e não podem ser facilmente reproduzidos: 
"[...] a humilde aura de autenticidade dos cadernos de recorte se mantém, mesmo quando seu conteúdo deixa de fazer sentido para o leitor." (OTT; TUCKER; BUCKLER, 2006, p. 12, tradução nossa).

Ora, não é preciso ir tão longe e buscar nas reflexões de Benjamin (2010) a respeito da "aura" das obras de arte os argumentos para reafirmar o caráter autêntico dos cadernos de recortes. Basta lembrar que, como documentos de arquivo, os recortes - compilados ou não em volumes encadernados - não gozam de estabilidade de sentido. Pelo contrário, assim como qualquer documento de arquivo, sua autenticidade e unicidade não se devem a uma suposta "aura", mas à condição orgânica da qual partilham com os demais documentos do fundo a que pertencem e do contexto imediato que preside sua produção e acumulação. Convém insistir: num arquivo, o sentido de cada documento (inclusive os recortes) se constrói na teia de relações implícitas e explícitas com os demais documentos que compõem a mesma série e, no limite, com o próprio fundo como um todo.

Casos concretos, extraídos de alguns arquivos pessoais (e que se replicam em tantos outros), podem jogar alguma luz sobre os atributos funcionais da prática de acumulação de recortes de jornal.

Antes, e mesmo depois, da proliferação dos periódicos científicos, a difusão do conhecimento especializado se dava, entre outros meios, pelas páginas dos jornais diários, que dedicavam - e ainda dedicam - espaço aos intelectuais e às personalidades do mundo da ciência. Não à toa, é comum encontrar as primeiras aulas e conferências proferidas pelos professores da Faculdade de Filosofia, Ciências e Letras da então recém-criada Universidade de São Paulo reproduzidas, muitas vezes na íntegra, nas páginas d'O Estado de S. Paulo, em meados da década de 1930.

Samuel Barnsley Pessoa (1898-1976), um dos mais destacados parasitologistas brasileiros, é apenas um exemplo, dentre muitos, da inserção do intelectual no espaço público por meio da imprensa. Catedrático da Faculdade de Medicina da USP e militante do Partido Comunista Brasileiro, Pessoa publicou cerca de 350 artigos científicos ao longo de sua carreira, além de livros que foram 
sucessivamente reeditados por muitos anos após seu falecimento. Em seu arquivo, sob custódia do Centro de Apoio à Pesquisa em História "Sérgio Buarque de Holanda", da Faculdade de Filosofia, Letras e Ciências Humanas da USP, podese verificar que o médico conservou também os recortes dos inúmeros artigos de divulgação que escreveu para jornais (muitos deles da chamada "imprensa nanica") e das entrevistas que concedeu. Estes recortes, muito mais do que possibilitar o acesso a uma produção significativa que dificilmente poderia ser recuperada em outros lugares, como as hemerotecas físicas ou digitais, oferecem um testemunho consistente de sua atividade autoral e da repercussão de sua obra, além de comprovarem os eventos consignados em seu currículo profissional (CAMPOS, 2014).

Razão semelhante parece justificar o ato de guardar recortes de jornal entre aqueles que se dedicaram à colaboração regular na imprensa, bem como à política ou às atividades - artísticas, científicas, literárias - passíveis de crítica especializada. Neste sentido, teria Carlos Drummond de Andrade (1902-1987) guardado os recortes de suas crônicas (são quase cinco mil) por constituírem prova e testemunho de sua atividade profissional ao longo dos trinta anos em que escreveu regularmente para o Correio da Manhã e para o Jornal do Brasil, ou seu gesto de arquivamento teria sido inspirado por uma vaidade velada, como especulam alguns ? $^{11}$

Se Drummond tratou de arquivar sua produção literária - fruto e prova de seu trabalho - de maneira metódica, organizando-a cronologicamente em dossiês, a escritora Lúcia Machado de Almeida preferiu fazê-lo, sem muito capricho, em cadernos escolares comuns, de folhas pautadas e espiral metálica, daqueles que podem ser comprados em qualquer papelaria, hoje amarelados pelo tempo e pela acidez dos recortes que abrigam. ${ }^{12}$ Por meio das notícias, resenhas e entrevistas coladas nas folhas destes cadernos, é possível acompanhar, de um lado, a repercussão de sua obra, e, de outro, sua circulação como figura da sociedade belo-horizontina. ${ }^{13} \mathrm{O}$ suporte pouco charmoso escolhido pela escritora mineira pode ser indicativo da função instrumental destes cadernos de recortes. Ou, num gesto de atribuição de sentido da parte de quem, hoje, lança a eles um olhar, 
sugeriria certo desinteresse ou até mesmo menosprezo por sua própria trajetória? Faz sentido supor que tivesse sido ela uma pessoa vaidosa, teria recortado com mais esmero, classificado os recortes por temas e produzido álbuns mais vistosos?

Neste mesmo fundo, outros recortes - soltos - chamam a atenção. São retratos de pessoas (muitas delas famosas) em poses inusitadas, destacadas das notícias e reportagens que originalmente se destinavam a ilustrar, sobre os quais Lúcia escreveu, à mão, títulos, legendas e diálogos. O volume do conjunto permite cogitar que estes recortes representem mais do que um mero passatempo: para além de revelarem um senso de humor bastante peculiar, poderiam ter sua funcionalidade estudada em relação ao processo criativo da escritora. ${ }^{14}$

Há também as situações em que os recortes de jornal parecem suprir as demandas ligadas à instrução, servindo ao acompanhamento sistemático de assuntos de interesse dos indivíduos, complementando, de certa forma, as bibliotecas pessoais e assumindo a condição de material de referência para a reflexão. É o que se pode notar na extensa coletânea de recortes acumulada por Jovina Álvares Pessoa, que perfaz aproximadamente $40 \%$ da extensão de seu arquivo. ${ }^{15}$ Quando observados em conjunto, é possível perceber a existência de um tema específico em torno do qual gravitam os recortes, revelador de uma área de interesse da titular do fundo: a política internacional. Conhecendo a biografia de Jovina Pessoa, militante do Partido Comunista Brasileiro e entusiasta de diversas causas sociais, é genuíno supor que a acumulação dos recortes se justifique em função da manifestação de seus interesses intelectuais (CAMPOS, 2017), hipótese que ganha força quando se observam as marcas, grifos e comentários apostos aos recortes, indícios consistentes de uma prática regular de leitura.

Os recortes de jornal, é bem verdade, não estão presentes apenas em arquivos de pessoas, mas também naqueles de natureza institucional. A condição instrumental dos recortes também pode ser evidenciada pela existência de um tipo de serviço oferecido por agências especializadas em monitorar a imprensa e selecionar, sob encomenda, matérias publicadas em jornais e revistas a respeito de determinados assuntos, visando a atender às necessidades informacionais de 
indivíduos e organizações. Trata-se do clipping, atividade que vem sendo desenvolvida comercialmente no Brasil desde 1928, quando da inauguração da Lux Jornal, empresa que se tornou uma das maiores em seu ramo de atuação.

Há pouco mais de 20 anos, O Estado de S. Paulo dedicou matéria de página inteira sobre o assunto. Apesar de ressaltar o reduzido número de empresas que, àquela altura, ainda atuavam no ramo, o texto revelava as cifras de um negócio lucrativo: em 1997, a Lux atendia a 1200 clientes, entre os quais grandes grupos corporativos como o Citibank e a Xerox do Brasil, distribuindo 600 mil recortes por mês. Até então, o avanço tecnológico e a crescente informatização da imprensa ainda não pareciam abalar negativamente o negócio; ao contrário, abriram espaço para a produção de clippings digitais. Naquele mesmo ano, outra empresa chegava a cobrar até 10 mil reais pela entrega de kits de recortes em CD (DIÓRIO, 1997). Mudaram-se os meios, os suportes, as técnicas, mas fato é que, ainda hoje, tanto a Lux quanto outras empresas congêneres continuam em atividade no país.

\section{4 À guisa de conclusão: desdobramentos}

Das atividades escolares desenvolvidas desde a infância à transformação dos recortes de jornal em objeto de consumo, passando pela preservação dos produtos da atividade profissional, pela manifestação dos exercícios criativos e pela coleção de material de referência para uso posterior, no sentido de subsidiar reflexões ligadas aos interesses intelectuais, políticos e culturais dos indivíduos, várias facetas do costume de recortar e colar se encaixam num mosaico que permite compreendê-lo como elemento de uma prática social que se reflete nos arquivos, sobretudo naqueles de natureza pessoal.

Para assimilar o lugar dos recortes de jornal nos arquivos e seu estatuto documental, convém observar algumas características básicas dos conjuntos de documentos organicamente constituídos. Para além da proveniência - princípio "primeiro, principal, natural e geral da ciência arquivística" (HEREDIA HERRERA, 2015, p. 44), que, no dizer de Bellotto (2002, p. 20), “[...] fixa a 
identidade do documento, relativamente ao seu produtor" -, do princípio da organicidade, segundo o qual "[...] os arquivos refletem a estrutura, funções e atividades da entidade acumuladora em suas relações internas e externas" (CAMARGO; BELLOTTO, 2012, p. 65), e do princípio da unicidade, pelo que os documentos de arquivo conservam seu caráter único em função do contexto em que foram produzidos (BELLOTTO, 2002), dois outros atributos são dignos de nota.

O primeiro deles tem força de princípio e compreende a lógica de formação dos arquivos: trata-se da cumulatividade. Os arquivos não nascem da acumulação deliberada, caprichosa de documentos; pelo contrário, sua formação atende a um movimento progressivo, natural e orgânico (BELLOTTO, 2002). E é justamente este caráter natural da acumulação que torna os arquivos comparáveis aos sedimentos das estratificações geológicas e "[...] os dota de um elemento de coesão espontânea, ainda que estruturada", como definiu Duranti (1994, p. 52).

Já o segundo se trata de uma elaboração sofisticada, extraída do contraste entre a lógica de produção e as possibilidades de uso dos documentos de arquivo. É a imparcialidade, noção enunciada por Hilary Jenkinson e mal compreendida, inclusive, por teóricos e profissionais da Arquivologia. Segundo o autor,

[...] a única predição, de fato, relativa aos interesses de pesquisa aos quais os arquivos podem servir é que, com apenas alguma exceção, estes não coincidem com as razões que inspiraram quem os acumulou e preservou. (JENKINSON, 1937, p. 12, tradução nossa).

Com efeito, há quem considere a noção de imparcialidade um ranço indesejado do positivismo. Ora, tendo produzido suas reflexões no início do século XX (a primeira edição de seu famoso manual data de 1922, antecedida por dois trabalhos sobre paleografia publicados em 1915), não se haveria de esperar que Jenkinson pudesse ter sido um relativista. Desta forma, a crítica que se faz às suas ideias resulta inócua e demonstra, no mais das vezes, uma leitura descontextualizada de sua obra. É o que se vê, por exemplo, em Lane e Hill (2011), quando não hesitam em atribuir a pecha de "neojenkinsonianos" a autores 
como Luciana Duranti e Michael Moss, que ousam falar em imparcialidade e objetividade quando se referem à natureza dos arquivos ou ao compromisso profissional do arquivista.

Como bem definiu Blanca Rodríguez-Bravo (2002, p. 143), “[...] o documento de arquivo nasce para dar vida à razão de sua origem”, isto é, não é produzido para que, no futuro, outras pessoas venham a estudá-lo, mas sim porque em determinado momento se deu um fato que, para que fosse comunicado ou para que pudesse ser reconhecido e validado no âmbito de um dado sistema jurídico, teve de ser passado para o meio escrito, na forma de um documento dotado dos elementos - ditados pelo Direito, pelas rotinas burocráticas ou mesmo pelos usos e costumes sociais - que lhes conferem autenticidade.

Ainda que os recortes de jornal não carreguem, de nascença, todos os atributos que, em tese, caracterizam o documento dito "arquivístico", nem sua acumulação responda, no mais das vezes, à força da obrigatoriedade, o que ocorre, vale sublinhar, com tantos outros espécimes encontrados nos arquivos pessoais, importa reconhecer que quando fazem parte de um fundo, os recortes revestem uma camada especial de sentido atrelada aos atributos funcionais determinados pelos contextos de acumulação e uso. É justamente este aspecto que diferencia a funcionalidade dos recortes nos diferentes espaços em que eles podem se manifestar: a hemeroteca, o centro de documentação de uma empresa jornalística ou o arquivo, independentemente da natureza institucional ou pessoal que caracterize sua proveniência.

Enquadrá-los em seu meio genético, isto é, nos diversos lugares lógicos que podem ocupar na estrutura do fundo a que pertencem, representados pelos grupos e subgrupos em que se dividem os planos de classificação ou quadros de arranjo e nos quais se distribuem as séries documentais, deve ser, naturalmente, a primeira preocupação do profissional de arquivo. Mas o reconhecimento do estatuto documental dos recortes não se completa com esta operação inicial. De pouco adianta classificá-los e arranjá-los em séries que, por fim, serão vagamente intituladas com expressões genéricas como "recortes de jornal", "produção de 
terceiros" ou "impressos", como usualmente se tem visto nos instrumentos de pesquisa.

Ora, se a série corresponde à "sequência de unidades de mesmo tipo documental" (CAMARGO; BELLOTTO, 2012, p. 76), é preciso dar a cada modalidade do discurso jornalístico encontrada sob o formato de recorte um nome capaz de exprimir, com clareza e objetividade, sua identidade no que tange aos seus aspectos estruturais internos e externos. Em outras palavras, é preciso identificar, estabelecer e definir espécies e tipos documentais. Para fazê-lo, não basta recorrer ao corpo de conhecimentos da Arquivologia, mas combiná-lo aos aportes de outros campos disciplinares, segundo a natureza dos documentos com que se trabalha. Neste sentido, a Diplomática é a disciplina que melhor vem de encontro aos interesses dos estudos tipológicos, mas ela, por si só, nem sempre é o bastante. No caso dos recortes de jornal, faz-se necessário o diálogo também com as Ciências da Comunicação, com a Teoria do Jornalismo, a Editoração, as Artes Gráficas, a Linguística, num exercício sofisticado - mas não impossível de combinação, transposição e articulação de conceitos e noções destas diferentes áreas do conhecimento: campo aberto a investidas, objeto para novos desdobramentos nos planos da teoria e da prática.

\section{Referências}

ALMEIDA, Paulo Nunes. Educação lúdica: técnicas e jogos pedagógicos. São Paulo: Loyola, 2003.

ARQUIVO PÚBLICO MUNICIPAL DE CAMPOS DOS GOYTACAZES.

Fundo Arquivo Cardoso de Melo: inventário analítico. Campos dos

Goytacazes: Fundação Cultural Jornalista Oswaldo Lima, 2005.

BASSEDAS, Eulàlia; HUGUET, Teresa; SOLÉ, Isabel. Aprender e ensinar na educação infantil. Porto Alegre: Artes Médicas, 2007.

BELLOTTO, Heloísa Liberalli. Arquivística: objetos, princípios e rumos. São Paulo: Associação de Arquivistas de São Paulo, 2002.

BENJAMIN, Walter. A obra de arte na época de sua reprodução mecanizada. Amadora: Escola Superior de Teatro e Cinema, 2010. 
BOURDIEU, Pierre. A distinção: crítica social do julgamento. 2. ed. Porto Alegre: Zouk, 2011.

BROADLEY, Alexander Meyrick. Chats on autographs. London: T. F. Unwin, 1910. Disponível em https://archive.org/details/chatsonautograph00broaiala. Acesso em: 19 fev. 2018.

CAMARGO, Ana Maria de Almeida. Arquivos pessoais são arquivos. Revista do Arquivo Público Mineiro, Belo Horizonte, ano 45, n. 2, p. 26-39, jul./dez. 2009.

CAMARGO, Ana Maria de Almeida; BELLOTTO, Heloísa Liberalli (coord.). Dicionário de terminologia arquivística. 3. ed. São Paulo: Associação de Arquivistas de São Paulo, 2012.

CAMPOS, José Francisco Guelfi. Facetas de um arquivo pessoal. In: FLORES, Débora; SANTOS, Andrea Gonçalves dos; CONRADO, Flavia Helena.

Arquivologia, sustentabilidade e inovação. Santa Maria: AARS, 2014. p. 932948.

CAMPOS, José Francisco Guelfi. Recortes de jornal: da prática social aos arquivos. 2018. Tese (Doutorado em História Social) - Faculdade de Filosofia, Letras e Ciências Humanas, Universidade de São Paulo, São Paulo, 2018.

CAMPOS, José Francisco Guelfi. Tipologia documental em arquivos pessoais: entre a arquivística e a diplomática. In: GARCÍA, Noelia; SILVA, Maria Celina Soares de Mello (org.). Archivos personales: experiencias de organización y gestión. Córdoba: Redes, 2017. p. 52-71.

CENTRO DE PESQUISA E DOCUMENTAÇÃO DE HISTÓRIA CONTEMPORÂNEA DO BRASIL. Metodologia de organização de arquivos pessoais: a experiência do CPDOC. 4. ed. Rio de Janeiro: Ed. FGV, 1998.

CERTEAU, Michel de. Ler: uma operação de caça. In: CERTEAU, Michel de. A invenção do cotidiano: artes de fazer. 16. ed. Petrópolis: Vozes, 2009. p. 236-263.

DIÓRIO, Rocheli. Mercado de clipping tem muito a crescer. O Estado de S. Paulo, São Paulo, p. 118, 8 jul. 1997.

DURANTI, Luciana. Registros documentais contemporâneos como provas de ação. Estudos Históricos, Rio de Janeiro, v. 7, n. 13, p. 49-64, 1994.

FUNDAÇÃO FERNANDO HENRIQUE CARDOSO. Glossário de termos utilizados na descrição do acervo. São Paulo: iFHC, 2015. Disponível em: http://acervo.ifhc.org.br/ModuloPesquisador/jsp/doctosApoio/1/glossario_docs. pdf. Acesso em: 21 fev. 2018. 
GARVEY, Ellen Gruber. Scissorizing and scrapbooks: nineteenth-century reading, remarking, and recirculating. In: GITELMAN, Lisa; PINGREE, Geoffrey B. (ed). New media, 1740-1915. Cambridge: The MIT Press, 2003. p. 207-227.

GOOD, Katie Day. From scrapbook to Facebook: a history of personal media assemblage and archives. New Media \& Society, [s. l.], v. 15, n. 4, p. 557-573, 2013.

HEREDIA HERRERA, Antonia. El principio de procedencia y los otros principios de la archivística. In: ANDRADE, Ana Célia Navarro de (org.). Archivos y documentos: textos seminales. São Paulo: Associação de Arquivistas de São Paulo, 2015. p. 43-56.

JENKINSON, Hilary. A manual of archive administration. 2nd. London: Percy, Lund, Humphries \& Co., 1937.

KISHIMOTO, Tizuko Morchida. O brinquedo na educação: considerações históricas. Idéias, São Paulo, n. 7, p. 39-45, 1995.

LANE, Victoria; HILL, Jennie. What do we come from? What we are? Where are we going? Situating the archive and archivists. In: HILL, Jennie (ed.). The future of archives and recordkeeping: a reader. London: Facet, 2011. p. 3-22.

LE BOULCH, Jean. O desenvolvimento psicomotor: do nascimento aos 6 anos. 4. ed. Porto Alegre: Artes Médicas, 1986.

LÉVI-STRAUSS, Claude. O pensamento selvagem. Campinas: Papirus: 1989.

MALUF, Angela Cristina Munhoz. Atividades lúdicas para educação infantil: conceitos, orientações e práticas. Petrópolis: Vozes, 2008.

NÃO se esqueça de arquivar suas receitas. O Estado de S. Paulo, São Paulo, p. 61, 20 mar. 1973.

OLIVEIRA, Zilma de Moraes Ramos de. Educação infantil: fundamentos e métodos. 7. ed. São Paulo: Cortez, 2011.

OTT, Katherine; TUCKER, Susan; BUCKLER, Patricia P. An introduction to the history of scrapbooks. In: OTT, Katherine; TUCKER, Susan; BUCKLER, Patricia P. (ed.). The scrapbook in American life. Philadelphia: Temple University Press, 2006. p. 1-28.

RABAÇA, Carlos Alberto; BARBOSA, Gustavo Guimarães. Dicionário de comunicação. 2. ed. Rio de Janeiro: Campus, 2001. 


\title{
RODRÍGUEZ-BRAVO, Blanca. EI documento entre la tradición y la
} renovación. Madrid: Trea, 2002.

ROSENTHAL, Margaret F. Fashions of friendship in an Early Modern illustrated album amicorum: British Library, MS Egerton, 1191. Journal of Medieval and Earcly Modern Studies, Durham, v. 39, n. 3, p. 619-641, 2009.

SAIBA como entreter seus filhos. O Estado de S. Paulo, São Paulo, p. 50, 7 set. 1956.

TRAVANCAS, Isabel. Entrando no arquivo de Drummond e lendo suas crônicas na imprensa. In: TRAVANCAS, Isabel; ROUCHOU, Joëlle; HEYMANN, Luciana (org). Arquivos pessoais: reflexões interdisciplinares e experiências de pesquisa. Rio de Janeiro: Ed. FGV, 2013. p. 229-247.

\section{Newspaper clippings in archives: origins of a social practice}

\begin{abstract}
The existence of newspaper clippings in archives, especially the socalled personal archives, challenges the archivists in theoretical and practical ways. Also, it allows us to presume that the accumulation of snippets reflects a social practice incipiently studied. This paper pursues the origins of that social practice and examines its multiple manifestations in the archives by an exploratory study based on literature review and documentary research. The literature review pointed-out the connection between the social practice of accumulating newspaper cuttings and the large, rich tradition of the scrapbooks, which seems to meet individuals' informational needs, the materialization of emotional bonds, and the building of cultural capital. The samples from documentary research highlighted the functional attributes determined by the contexts in which the snippets were accumulated and used by individuals. On the one hand, these attributes endorse archival processing grounded in the principles and procedures of Archival Science. On the other hand, they emphasize the relevance of studying the documentary forms in dialogue with other disciplines such as Diplomatics, Communication Studies, Theory of Journalism, and Linguistics.
\end{abstract}

Keywords: Newspaper clippings. Scrapbooks. Social practice. Personal archives. Documentary form.

Recebido: 09/06/2020

Aceito: 07/08/2020

\section{Declaração de autoria}

Concepção e elaboração do estudo: José Francisco Guelfi Campos

Coleta de dados: José Francisco Guelfi Campos

Análise e discussão de dados: José Francisco Guelfi Campos 


\section{Redação e revisão do manuscrito: José Francisco Guelfi Campos}

\section{Como citar}

CAMPOS, José Francisco Guelfi. Recortes de jornal em arquivos: origens de uma prática social. Em Questão, Porto Alegre, v. 27, n. 2, p. 52-75, abr./jun. 2021. Doi: http://dx.doi.org/10.19132/1808-5245272.52-75

${ }^{1}$ Não entraremos, aqui, na discussão a respeito da atualidade do termo "arranjo", considerado ultrapassado por certos estudiosos e profissionais, tendo em vista que, é bem verdade, comporta certa compatibilidade com os procedimentos da classificação. Com efeito, acreditamos que o arranjo, aplicado aos arquivos permanentes, pode se desdobrar em operações de cunho intelectual (definição dos níveis em que se estrutura a representação da lógica interna do arquivo, o que não significa necessariamente mera extensão ou adaptação de um plano de classificação previamente elaborado, caso ele exista) e prático (ordenação das unidades reais e concretas que preenchem aquela estrutura lógica, isto é, os documentos propriamente ditos). Contudo, convém sublinhar que estas duas facetas do arranjo, quais sejam, a ordem intelectual e a ordenação física, são independentes e se orientam por métodos e procedimentos que lhes são próprios.

${ }^{2}$ Exemplos destas situações podem ser encontrados nas descrições dos arquivos de Cyro dos Anjos (Acervo de Escritores Mineiros, Universidade Federal de Minas Gerais) e de Ubaldino do Amaral (Fundação Casa de Rui Barbosa). https://www.ufmg.br/aem/Inventario_cyro/layout_cyro.htm http://www.docvirt.com/DocReader.net/DocReader.aspx?bib=FCRBUbaldino. Acesso em: 31 jan. 2018.

${ }^{3}$ Entendemos o conceito de série segundo a definição do Dicionário de terminologia arquivística: "Sequência de unidades de um mesmo tipo documental" (CAMARGO; BELLOTTO, 2012, p. 76).

4 “Album amicorum: Marnix de St. Aldegonde: 1579-1623”, British Museum, Sloane MS 851.

5 “Album amicorum Johannis Breijsgen, 1572-1577”, British Museum, Egerton MS 679.

${ }^{6} \mathrm{O}$ álbum pertence ao acervo da Koninklijke Bibliotheek (Biblioteca Nacional dos Países Baixos) e pode ser consultado no portal da Biblioteca Digital Mundial, iniciativa da Library of Congress (Estados Unidos) e da UNESCO. Disponível em: https://www.wdl.org/pt/item/14421/. Acesso em: 21 fev. 2018

${ }^{7}$ Segundo o glossário da Fundação Fernando Henrique Cardoso (2015, p. 5-6), o caderno de enquete "circula entre colegas da escola para que nele registrem suas preferências e opiniões sobre assuntos diversos".

${ }^{8}$ Durante a pesquisa da qual deriva este artigo, procedemos à revisão de edições completas de dois diários paulistas de grande circulação publicadas entre os anos de 1930 e 2000 . Neste esforço, pudemos observar que a organização do conteúdo das entrevistas se dava, até meados do século, preferencialmente em texto corrido, intercalando-se os discursos direto e indireto. A transformação da entrevista em diálogo, marcado pelo discurso direto, vai de encontro ao movimento de renovação do estilo jornalístico que, no Brasil, se dá por volta da década de 1960.

${ }^{9}$ Confessions (An album to record opinions, thoughts, feelings, ideas, peculiarities, impressions, characteristics), 16/05/1888. Musée Rodin, Archives, Ms. 368. Disponível em: http://www.musee-rodin.fr/fr/collections/archives/confessions. Acesso em: 22 fev. 2018.

${ }^{10}$ Caderno de enquete. São Paulo, 1945-1948. Fundação Fernando Henrique Cardoso, Acervo Fernando Henrique Cardoso, 14/0000008. Disponível em: http://acervo.ifhc.org.br. Acesso em: 20 fev. 2018.

${ }^{11} \mathrm{O}$ arquivo de Carlos Drummond de Andrade é custodiado pelo Arquivo-Museu de Literatura Brasileira da Fundação Casa de Rui Barbosa. A respeito das relações entre os sentidos projetados sobre seu conjunto documental e a personalidade do poeta, ver Travancas (2013).

12 Acervo de Escritores Mineiros - UFMG, Acervo Lúcia Machado de Almeida, série produção intelectual de terceiros, subsérie recortes de jornais e revistas, dossiês cadernos de recortes (1 a 4). 
${ }^{13}$ Lúcia Machado de Almeida (1910-2005) se notabilizou no campo da literatura infanto-juvenil, tendo recebido, entre outros prêmios, o Jabuti em 1968. O escaravelho do diabo, originalmente publicado como folhetim em $O$ Cruzeiro (1953) e depois editado em livro (1974), tem sido sucessivamente reeditado e chegou a ser adaptado para o cinema em 2016.

${ }^{14}$ Acervo de Escritores Mineiros - UFMG, Acervo Lúcia Machado de Almeida, série produção intelectual de terceiros, subsérie recortes de jornais e revistas, pastas 1 e 2.

15 Jovina Álvares Pessoa (1897-1988) era farmacêutica de formação e dirigiu o Departamento Social da União Feminina Paulista. Foi casada com o parasitologista Samuel Barnsley Pessoa e o secretariou durante sua atuação em comitê para o estudo dos efeitos da guerra bacteriológica na Coréia, na década de 1950. Militou pela anistia de presos políticos durante a ditadura militar e foi, também, professora primária e alfabetizadora de adultos. Seu arquivo é custodiado pelo Centro de Apoio à Pesquisa em História "Sérgio Buarque de Holanda", da Faculdade de Filosofia, Letras e Ciências Humanas da USP. 